\title{
Building English Vocabulary Schema and Words Retention using Review Value Calculation for English as Secondary Language Students
}

\author{
Burnhan Mustafa Tanis ${ }^{1 *}$, Melvin A. Ballera ${ }^{2}$, Mosbah Mohamed Elssaedi ${ }^{3}$ \\ 1 AMA University - School of Graduate Studies, Philippines \\ 2 Technological Institute of the Philippines - Manila, Philippines \\ ${ }^{3}$ Faculty of Science - Computer Science, Sirte University, Libya
}

DOI: https://doi.org/10.21467/proceedings.2.6

*Corresponding author email: burnhanmt@ outlook.com

\begin{abstract}
Vocabularies, the core of any language, is probably the most challenging and time consuming part of learning a foreign language in a diverse and disperse community of learners. This study proposes an approach that can help a learner build up his/her English vocabulary volume by intensive article reading, the inclusion of Google Cloud Natural Language API and Glosbe Dictionary API, the use of review value calculation computing technique. The review vale calculation were able to determine the number of days were the new words should be reviewed and be part of the long-term memory. Result shows that students were able to increase their words acquisition skills by applying technology and computing. Students were able to retain words fast and understand better, by employing an interactive monitoring process. If the system will be implemented carefully, it is hypothetically produce a faster technique in acquiring new vocabularies for foreign students.
\end{abstract}

Keywords: Vocabulary schema, review value calculation, short term memory, long term memory, assessment interval

\section{Introduction}

E-learning has been used to help students learn the English language in their own convenient time and place [1]. It has become a large industry offering online lessons to students with the use of video-conference system. Video conferencing fosters communication and collaboration and trainee-teachers and can jointly dissect the newly acquired knowledge [2] [3]. The author [4] concluded that video conferencing is a "powerful tool" to give students confidence in innovative teaching practices. More students view it as a great alternative to learning the English language outside the classroom. They see it as new age education systems that can bring knowledge in an updated form. Vocabulary is one of the critical part of learning English language. It is a fundamental way to comprehend whatever the student hears, reads

(C) 2018 Copyright held by the author(s). Published by AIJR Publisher in Proceedings of First Conference for Engineering Sciences and Technology (CEST-2018), September 25-27, 2018, vol. 1.

This is an open access article under Creative Commons Attribution-NonCommercial 4.0 International (CC BY-NC 4.0)

AiR license, which permits any non-commercial use, distribution, adaptation, and reproduction in any medium, as long as the original work is properly cited. ISBN: 978-81-936820-5-0 
Building English Vocabulary Schema and Words Retention using Review Value Calculation for English as Secondary Language Students and most importantly, how the person communicates to the world. It is known to be one of the hardest of acquiring the knowledge to speak the English language, but it is often overlooked. With more teachers and learners giving priorities to Grammar and Reading Skills, students have a hard time learning and retaining the words that they have learned. They immediately forget the words after the teacher has given them the meaning or even after looking at the dictionary. A lot of studies suggested on how students can improve their vocabulary. One of the best would be through reading.

A long-term habit of extensively reading articles that are appropriate for a learner's English ability can greatly improve the vocabulary and command of a learner of English. However, this strategy may be difficult to implement for a learner with no extensive vocabulary because the learner may have problems either in choosing appropriate levels of articles in accordance with her/his needs and interests or in figuring out the meaning of unknown words using the semantics of familiar words in an article that is obtained. Dictionaries are always helpful; however, the need to continually look up unknown words, which once learned may be forgotten in a few days as per learning curve theory, might also easily discourage a learner. Several studies have also developed language tutoring systems in order to assist learners in learning language and have also proposed different personalization strategies [5].With regard to an e-learning system, it is also hard to select appropriate articles for such learners if details on or precise profiles of learners are never established.

This study proposes an approach that can help a learner build up his/her English vocabulary volume by intensive article reading, during which meanings of unknown words are understood in the context of articles, assessment test and the used of evolutionary computer science technique, the review value calculation for determining vocabulary memory retention. The intention is to obtain the vocabulary from articles more affective, so learners will not easily forget the words.

\section{Related Literature}

Vocabulary learning is the area in which learners use learning strategies most frequently [6]. Oxford defines learning strategies as "operations employed by the learner to aid the acquisition, storage, retrieval and use of information". Vocabulary learning has been classified into two ways the traditional vocabulary learning and technology savvy vocabulary learning. Traditional vocabulary learning prepare selected vocabulary lists to assist learners and claim that such lists can reinforce students' memories and understanding of the words. However, it is impossible to compile a vocabulary list that is appropriate for all the students in a class with different English levels [7]. Another study used keyword method as the best memory technique for learning concrete words but not abstract words [8]. Another suggests that the use of vocabulary notebook/index cards can be an effective shortcut to achieve [9]. Ideally, the words recorded in the notebook/index cards are chosen according to the need of individual learners, thus learner autonomy is raised. As a matter of fact, learner autonomy and 
its effectiveness have been widely recognized. One way to aid vocabulary acquisition is through the use of technology in pedagogically sound manner [10]. Semantic mapping is a popular strategy used in classrooms. Learners are encouraged to use concepts and relationships to create a semantic map in which keywords are highlighted. Linkage is formed between the above information and the new word so as to reinforce the memory of the new word. Researchers have both positive and negative comment toward this method [11]. It is also interesting to note that both traditional and technology savvy technique is worthy to mention however there still a need to address and develop new innovative ways to improve learning in vocabulary acquisition using deterministic peer review calculation that deals with words retention and acquisitions.

\section{Vocabulary Architecture and Methods}

Figure 1 shows the English vocabulary schema building processes which are composed of four phases: assessment phase, practicing phase, vocabulary acquisition phase, and the actual acquisition phase. During assessment phase, the level and interest of the learner will be initially assessed to create learner's vocabulary schema, profiles and a personalized learning process. The establishment of interest and level of the student (based on European standard), the system is capable of rendering $25-40$ articles, depending on the information taken during the initial assessment. As the learning process progress, short quizzes will be given based on the learner's vocabulary schema to determine learner's comprehension.

Practicing phase on the other hand is capable of helping learners through human English native speakers subject to the availability of online Instructor. Usually, learners will request an online instructor for actual mentoring and tutoring. Results will then be recorded for profiling the learner's vocabulary schema. When the user requested to speak to a native speaker, the system will find a teacher that is available at that time in the system. The native speaker will then be given enough time to review the student's level and vocabulary schema before speaking to the student.

Vocabulary acquisition phase is a stage where an article will be presented based on learner's level, interest and profiles. The article is directly link to the Google Cloud Natural Language Application Programming Interface (API) to determine parts of speech and grammars rules, lemmatization and stemming while Instructor define vocabularies that needs to be learned by the learners. Actual acquisition stage define the meaning of the vocabularies, employing Glospe Dictionary API to define the vocabulary according to the localized definition of words and language conversion from language to another e. g. English to Spanish and to other recognized languages. 


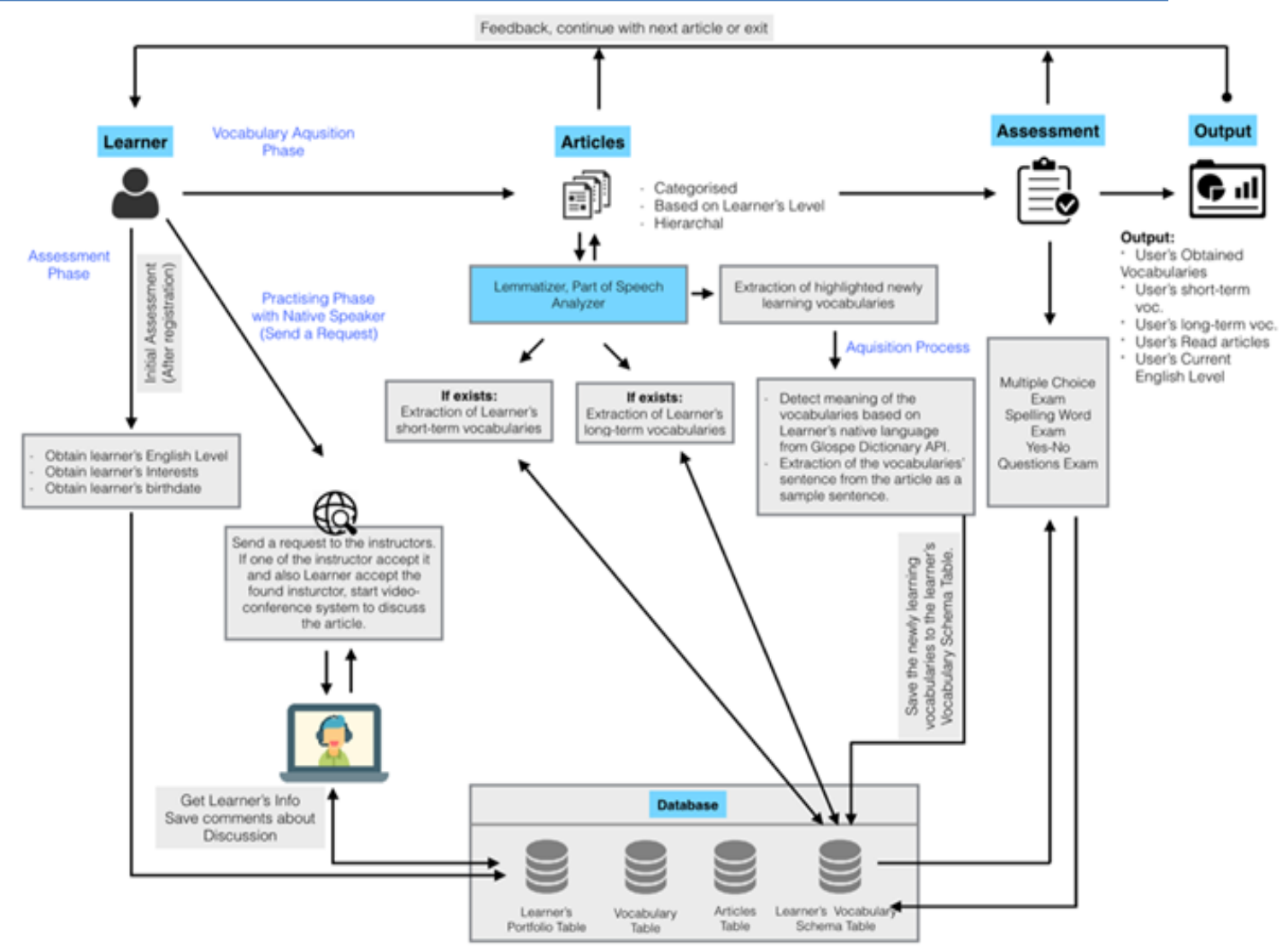

Figure 1: The vocabulary learning processes of the system

In the learning process and acquiring new words, the review value calculation will dynamically computed to determine reinforcement (reading related articles), adjustment (quizzes) to make sure that new vocabularies will be learned. The higher the value of review value calculation the higher its memory retention. There are four essential table that will keep the progress and assessment of the leaner: learner's portfolio table, learner's vocabulary schema table, general vocabulary table and article table. These tables will contain the entire learner's information such as interest, level and articles which will be saved automatically. This is where Review Value Calculation Module will get all the information before giving the user the appropriate articles to read, vocabulary to use in the articles and quizzes to give.

Looking at the conditions, if the learner gets lower than 3 out of the given 4 questions, learner stays in the same level, but on the other hand, if the learner gets 3 or more he would then move on to the next succeeding questions until the system finds his rightful level. To determine the acquisition of a new vocabulary, short-term and long-term should be determined using the concepts of review value calculation or rvc. Short-term refers to any newly obtained vocabulary in the system. When user obtains a new vocabulary it will be marked as a default short-term. Each newly obtained vocabulary is ranked as 1 in the user's vocabulary schema. As the words continuously appearing in the quizzes its rank increases. The system will compute 
the assessment interval or $A i$ as shown in (1). The lower the rank of the word, the more it would appear in assessment so the learner could master that particular word. If the words reaches rank 4 then it will be transferred to long term memory.

$$
A i=(\operatorname{round}(0.5 * r c)+(2 * s p)+(2 * \text { riec })) * r g
$$

The assessment interval, $A i$ is computed in terms of days. The next assessment for that particular vocabulary is after 36 days. A quiz containing that word would then appear and if the learner gets it correctly, a new assessment interval would then take places and it could appear - depending on the system's calculation, a month, a year or so. Nevertheless, after 36 days interval and an assessment happen, if the user got it wrong, it would be degraded again into short-term.

\section{$4 \quad$ Results And Discussion}

For brevity, figures and tables have been restructured; only 20 out of 50 learners have been used for discussion. A total of 50 students were extracted from 1000 possible learners of the company. Table 1 shows the initial level of learners from different countries doing online courses of English Communication, mostly from Turkish, Russian, European and Central Asian. The age average is 24.5 with standard deviation of 1.25 . The area of interest is adventure while English level is ranging from beginners level A1 to B1.

Table 1: Users' profile and initial assessment result

\begin{tabular}{|c|c|c|c|c|c|c|}
\hline$\#$ & Name & Family Name & Initial Level & Vocabulary Area & Age & User's Native Lang. \\
\hline 1 & Kubilay & Künç & A2 & \begin{tabular}{|l|} 
Adventure \\
\end{tabular} & 34 & Turkish \\
\hline 2 & Numan & Numan & A1 & Adventure & 42 & Turkish \\
\hline 3 & Mücella & Celik & $A 2$ & Adventure & 20 & Turkish \\
\hline 4 & Zeynep & Pampal & A1 & Adventure & 17 & Turkish \\
\hline 5 & Ōmer & Mindivanli & B1 & Adventure & 22 & Turkish \\
\hline 6 & Ahmet Turan & Bakır & A2 & Adventure & 23 & Turkish \\
\hline 7 & Furkan & Pehlivan & A1 & Adventure & 21 & Turkish \\
\hline 8 & Selman Kasim & BAĞIRICl & $\mathrm{A} 2$ & Adventure & 17 & Turkish \\
\hline 9 & Ibrahim & Özsūrücū & B1 & Adventure & 19 & Turkish \\
\hline 10 & Adalet & Arıkanoğlu & B1 & Adventure & 20 & Turkish \\
\hline 11 & \begin{tabular}{|l|} 
U.̆̈ur \\
\end{tabular} & Ozdemir & A2 & Adventure & 25 & Turkish \\
\hline 12 & Ahmet & Söyler & A2 & Adventure & 26 & Turkish \\
\hline 13 & Öznur & Karakılınç & A1 & Adventure & 30 & Turkish \\
\hline 14 & Яна & Елфимова & A1 & Adventure & 24 & Russian \\
\hline 15 & Barıș KARSLI & KARSLI & A1 & Adventure & 22 & Turkish \\
\hline 16 & ле̌ша & ЯH & A2 & Adventure & 21 & Czec Rep. \\
\hline 17 & Mustafa & Onat & A1 & Adventure & 19 & Turkish \\
\hline 18 & \begin{tabular}{|l} 
Leopoldo \\
\end{tabular} & Datuin & B1 & Adventure & 33 & Moldova \\
\hline 19 & Orxan & Ismayilov & A1 & Adventure & 19 & Azerbaijan \\
\hline 20 & EMRE & ULAKCு & A2 & Adventure & 32 & Turkish \\
\hline
\end{tabular}

It has shown that the participants have almost the same level considering their age and nationalities. This may be probable due to less exposure of English language on these 
Building English Vocabulary Schema and Words Retention using Review Value Calculation for English as Secondary Language Students

countries. The development process of vocabulary schema was divided into three parts, namely: will be obtained, newly obtained and obtained vocabulary words.

Table 2 shows the status of the 20 learners with their corresponding records given the articles in the area of adventures. The third column corresponds to the target vocabulary or will be obtained vocabularies. For student number 1 for example, it requires to have a 110 to be obtained vocabularies but 78 were obtained with rendered 10 articles out of 15 articles and etc. All these are all part of showing the students' progress throughout their journey in enhancing their vocabulary schema and learning English.

Table 2: Learners profile on target vocabulary and number of articles

\begin{tabular}{|c|c|c|c|c|c|c|c|c|c|}
\hline$\#$ & Name & Family Name & Target Vocabulary & Vocabulary Area" & Obtained Vocabulary & User's Native Lang. & Article Level & Total Article & Finished Article \\
\hline 1 & Kubilay & Künç & 110 & Adventure & \begin{tabular}{|l|}
78 \\
\end{tabular} & \begin{tabular}{|l|} 
Turkish \\
\end{tabular} & $A 2$ & 15 & 10 \\
\hline 2 & Numan & Numan & 100 & Adventure & 80 & Turkish & A1 & 22 & 18 \\
\hline 3 & Mûcella & Çelik & 110 & Adventure & 80 & Turkish & $A 2$ & 15 & 18 \\
\hline 4 & Zeynep & Pampal & 100 & Adventure & 50 & Turkish & A1 & 20 & 10 \\
\hline 5 & Ömer & Mindivanli & 113 & Adventure & 45 & Turkish & $B 1$ & 20 & 7 \\
\hline 6 & Ahmet Turan & Bakıf & 115 & Adventure & 45 & Turkish & A2 & 15 & 8 \\
\hline 7 & Furkan & Pehlivan & 100 & Adventure & 45 & Turkish & A1 & 20 & 12 \\
\hline 8 & Selman Kasim & BAĞIRICI & 115 & Adventure & 70 & Turkish & A2 & 15 & 11 \\
\hline 9 & Ibrahim & Ozsūrücū & 113 & Adventure & 50 & Turkish & $B 1$ & 20 & 7 \\
\hline 10 & Adalet & Arikanoğlu & 113 & Adventure & 60 & Turkish & $B 1$ & 20 & 9 \\
\hline 11 & Uğur & Özdemir & 115 & Adventure & 70 & Turkish & $A 2$ & 15 & 13 \\
\hline 12 & Ahmet & Söyler & 115 & Adventure & 50 & Turkish & A2 & 15 & 9 \\
\hline 13 & Oznur & Karakilinç & 100 & Adventure & 40 & Turkish & A1 & 25 & 12 \\
\hline 14 & Яна & Елфимова & 100 & Adventure & 40 & Russian & A1 & 22 & 12 \\
\hline 15 & Banı KARSLI & KARSLI & 100 & Adventure & 60 & Turkish & A1 & 22 & 15 \\
\hline 16 & ภёша & ЯH & 115 & Adventure & 80 & Czec Rep. & A2 & 22 & 18 \\
\hline 17 & Mustafa & Onat & 100 & Adventure & 90 & Turkish & A1 & 22 & 20 \\
\hline 18 & Leopoldo & Datuin & 113 & Adventure & 50 & Moldova & $B 1$ & 20 & 10 \\
\hline 19 & Orxan & Ismayilov & 100 & Adventure & 70 & Azerbaijan & A1 & 22 & 17 \\
\hline 20[ & EMRE & ULAKC,I & 115 & Adventure & 60 & Turkish & A2 & 22 & 11 \\
\hline
\end{tabular}

Apart from the front-end of the system, another major component to consider as to how review value calculation algorithm is implemented to support improving the learner's vocabulary schema is considering the back-end, formula used in finding the assessment of interval. Assessment interval defines the schedule on when that particular vocabulary should appear in the quiz. Considering the performance during exam counter, how many times the word appeared in the articles and did the learner conduct a speaking practice with the lecturer online, are the components of finding the assessment interval. For discussion, student number 2 were taken and extracted for discussion.

Applying the formula discussed in previous section, Table 3 derived the attributes of vocabulary_id 62, and the assessment interval of the vocabulary will be assessed after 4 days. Looking at the created_at entry, this shows when the vocabulary was first seen and if it appears in other articles updated_at will be refreshed. But based on the assessment interval, if the particular word was created last 2017-11-29, a quiz will be given to the learner four days later (2017-12-03) regarding the vocabulary.

This approach is actually seen in General English Proficiency Test, GEPT, in Taiwan as early as 2000. Same vocabulary and articles used in different levels of GEPT for different levels of 
Tanis et al.., CEST-2018, AIJR Proceedings 2, pp.43-51, 2018

English abilities. In addition to adjusting memory cycles of vocabulary (Wang, 2012), it also infers the relationships between words in an article and intelligently adjusts the memory cycles of those words that do not appear in the after-reading quizzes but are known to a learner. This approach does not only enhance the learner's vocabulary schema but also checks the learnt word from time-to-time with assessment interval.

Table 3: The assessment interval of a particular student

\begin{tabular}{|c|c|c|c|c|c|c|c|c|c|c|c|}
\hline & user_id & av id & vocabulary_id & ranking & review_counter & review_in_exam_counters & tspeaking_practice_counter & assessment interval & inext_assessment_dt & tcreated_at & updated_at \\
\hline 85 & 2 & 66 & 62 & 1 & \begin{tabular}{|l|}
3 \\
\end{tabular} & \begin{tabular}{|l|}
1 \\
\end{tabular} & 0 & 4 & $2017 \cdot 12 \cdot 03$ & 2017-11.29 18::46 & \begin{tabular}{l|l|}
$6017-11 \cdot 29$ & $18: 11$ \\
\end{tabular} \\
\hline 87 & 2 & 65 & 61 & 1 & 1 & 1 & 0 & 3 & $2017 \cdot 12 \cdot 02$ & 2017-11-29 18:i:46 & \begin{tabular}{l|l|}
$6017-11 \cdot 29$ & $18: 446$ \\
\end{tabular} \\
\hline 88 & 2 & 64 & 60 & 2 & 1 & 2 & 0 & 5 & $2017 \cdot 12.04$ & 2017.08-10 18:15 & \begin{tabular}{|l|l|}
$2017-11 \cdot 29$ & $18: 119$ \\
\end{tabular} \\
\hline 89 & 2 & 63 & 59 & 1 & 1 & 1 & 1 & 5 & $2017 \cdot 12 \cdot 04$ & 2017-11-29 18:i:46 & \begin{tabular}{|l|l|}
6 & $2017-11 \cdot 29$ \\
\end{tabular} \\
\hline 84 & 2 & 58 & 55 & 1 & 5 & 1 & 1 & 7 & $2017-12.06$ & 2017-11-29 18:i:46 & \begin{tabular}{l|l|}
$6017-11-29$ & $18: 19$ \\
\end{tabular} \\
\hline 86 & 2 & 57 & 54 & 2 & 3 & 2 & 1 & 8 & $2017 \cdot 12 \cdot 07$ & 2017-08-10 18:1:19 & 2017-11-29 18:19 \\
\hline 83 & 2 & 56 & 53 & 1 & 3 & 1 & 1 & 6 & $2017 \cdot 12.05$ & 2017-08-10 18:1:19 & 2017-11-29 18::46 \\
\hline 78 & 2 & 55 & 52 & 1 & 2 & 1 & 1 & 5 & $2017 \cdot 12.04$ & 2017-08-10 18:1:19 & 2017-11.29 18:i:46 \\
\hline 82 & 2 & 53 & 50 & 3 & 1 & 3 & 1 & 9 & $2017 \cdot 12.08$ & 2017-08-10 18:15 & 2017-11-29 18::46 \\
\hline 81 & 2 & 52 & 49 & 1 & 2 & 1 & 0 & 4 & $2017 \cdot 12 \cdot 03$ & 2017.08-10 18:19: & 2017-11-29 18:i46 \\
\hline 80 & 2 & 51 & 48 & 1 & 3 & 1 & 0 & 4 & $2017 \cdot 12 \cdot 03$ & 2017-11-29 18:i:46 & \begin{tabular}{l|l|}
$6017-11 \cdot 29$ & $18:: 46$ \\
\end{tabular} \\
\hline 77 & 2 & 50 & 47 & 3 & 1 & 3 & 0 & 7 & $2017 \cdot 12 \cdot 06$ & 2017-11-29 18i:46 & \begin{tabular}{l|l|}
$6017-11 \cdot 29$ & $18:: 46$ \\
\end{tabular} \\
\hline 79 & 2 & 49 & 46 & 1 & 1 & 1 & 0 & 3 & $2017 \cdot 12 \cdot 02$ & 2017-11-29 18:4:46 & 6 2017-11-29 18::46 \\
\hline 76 & 2 & 48 & 45 & 1 & 1 & 1 & 0 & 3 & $2017 \cdot 12 \cdot 02$ & 2017-11-29 18i:46 & \begin{tabular}{l|l|}
$6017-11 \cdot 29$ & $18:: 46$ \\
\end{tabular} \\
\hline
\end{tabular}

Figure 2 shows the monitoring of individual progress of the user in terms of his/her vocabulary schema. It includes the number of gained short-term and long-term vocabularies. This graphic illustration is presented for visual and vivid purposes. Out of 67 new acquired vocabularies 10 of which were converted into long-term while the other is currently active based on read articles. Clicking the show button in Figure 2 will show all the new vocabularies learnt by the learner. The vocabulary, type of figure of speech and its translation are all shown to serve as if a dictionary of its own and refer as the vocabulary schema. Learners can easily track his/her own progress with a click in his/her most convenient time. The used of review value calculation provide essential factor to support improving the learner's vocabulary schema is through the promotion of the learner from one level to another. For instance, the system can shows and monitor students who makes progress by increasing its level. For example student 2 was able to obtain 100 new vocabularies and after taking a handful of quizzes; he would be promoted to A2.

Vocabulary, the core of any language, is probably the most challenging and time consuming part of learning a foreign language. It takes time and flows like a continuous process, once you have settled the fundamentals of a language (pronunciation, orthography and basic grammar). Throughout this process, learners become familiarized with the words they come across. It is the frequency of usage and the number of encounters in different forms and contexts that determine the acquisition of new vocabulary. When teaching vocabulary, the context is really 
Building English Vocabulary Schema and Words Retention using Review Value Calculation for English as Secondary Language Students important that is why some authors underlines the important words that can be used for real communication [12].

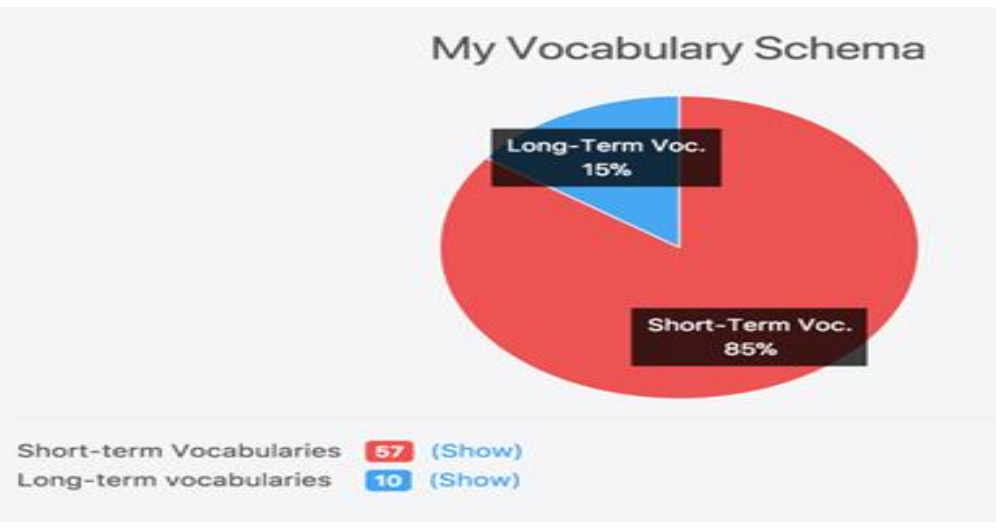

Figure 2: Long-term vs. short-term vocabulary

The great challenge for teachers to design individual and group activities using the Internet resources is how to explore different cultures more directly and effectively [13]. University language learners studying English as additional subject, still have problems in acquiring vocabulary. The assumption is that this might be due to the strategies used in teaching vocabulary. Thus, language teachers and researchers started considering technology as an option to teach more effectively. It seems that learners show very little effort to deal with their problems about newly learned words when technology is involved. During the lesson teachers often assume that students will deal with this problem of vocabulary building outside the class on their own. However, learners do not have enough knowledge about the vocabulary learning techniques and they have difficulty in dealing with this problem themselves [14].

\section{Conclusion}

Learning new vocabulary is one of the most challenging and time eating processes of foreign learners. Several vocabulary type of researches have navigated this area of tutoring and successfully implemented in different manners. The study focus on learning new vocabulary by rendering articles for reading based on the user interest and entry level thereby progressing in due time. To make sure that the acquisition of vocabulary will happen, a computing mechanism has been incorporated into the system using review value calculation. By it used, learners were able to monitor their progress and vocabulary acquisition by transferring to longterm memory from short term memory. Based on the results many foreign students were able to demonstrate fast comprehension and understanding. Almost all the student increased their English level according to European English Level Framework. Although the study is successfully implement, computing mechanism in words acquisition, there is a need to have an intelligent system to help the learners to advance in words acquisition. For example, a presence of an artificial intelligence to teach the student and encourage them to continue is 
needed for faster words acquisition. Another proposal is to transform the learning process into a game based tutoring system in acquiring new vocabularies.

\section{References}

[1] Kritikou, Yioli (2013).Cognitive Web-Based Vocabulary Learning System: The Results Of A Pilot Test Of Learning Greek As A Second Or Foreign Language. Procedia - Social and Behavioral Sciences 141 ( 2014 ) 1339 - 1345.

[2] Johnson, T.E, Maring, G.H., Doty, J.H., \& Fickle, M. (2006). Cybermentoring: Evolving High-End Video Conferencing Practices to Support Preservice Teacher Training. Journal of Interactive Online Learning 5(1), 59-74.

[3] Hu, C. \& Wong, A. F. L. (2006). Video Conferencing by Student Teachers: Does it Make Any Difference? New Horizons in Education, (53), 42-56.

[4] Kent, A. M., Simpson, J. L. (2010). Interactive videoconferencing: Connecting theory to practice for pre-service teachers. Journal of Digital Learning in Teacher Education, 27(1), 12-21.

[5] Atkinson J. (2009). Designing a feedback component of an intelligent tutoring system for foreign language. Knowledge-Based Systems, 22(7), 496-501.

[6] Klapper, J. (2008) 'Deliberate and incidental: vocabulary learning strategies in independent second language learning', in Hurd, S. and Lewis, T.,(eds.) (2008) Language Learning Strategies in Independent Settings, vol. 33, Clevedon, Multilingual Matters.

[7] Graham, S.,Harris, K.R., and Loynachan, C. (1993). Journal of Educational Research 86 (6): 363-368.

[8] Stoller, F.L., \&Grabe, W. (1993). Implications for L2 vocabulary acquisition and instruction from L1 vocabulary research in Huckin T., Haynes, M., and Coady, J. (eds.), Second language reading and vocabulary learning, pp.2445. Norwood, New Jersey: Ablex.

[9] Schmitt, N. \& Schmitt, D. (1995). Vocabulary notebooks: theoretical underpinnings and practical suggestions.ESL Journal 49(2): 133-143.

[10] Sahin, Mehmet. (2009). Computer Assisted Instruction in Aiding Second- Language Learners. Eurasian Journal of Educational Research. Issue 34. Pp. 115-132.

[11] Nation, I.S.P. (1990). Teaching and learning vocabulary. Boston. Heinle and Heinle Publishers.

[12] Warschauer, M. (1995). E. Mail for English Teaching. Alexandra, VA: TESOL Publications. The role of using Facebook in improving English, TOJSAT : The Online Journal of Science and Technology- July 2013, 3 (1).

[13] Nadar, R. (1996) Digital democracy in action, Forbes. 2 December: 49, The role of using Facebook in improving English TOJSAT : The Online Journal of Science and Technology- July 2013, Volume 3, Issue 1

[14] Monica S., \&Mirabela P. A. (2014). The Impact of Social Media on Vocabulary Learning Case Study Facebook. http://steconomiceuoradea.ro/anale/volume/2014/n2/013.pdf 